J. Dairy Sci. 99:7495-7505

http://dx.doi.org/10.3168/jds.2016-11142

(C) 2016, THE AUTHORS. Published by FASS and Elsevier Inc. on behalf

of the American Dairy Science Association ${ }^{\circledR}$. This is an open access article under

the CC BY-NC-ND license (http://creativecommons.org/licenses/by-nc-nd/3.0/).

\title{
Identifying risk factors associated with lameness in pasture-based dairy herds
}

\author{
S. Ranjbar, ${ }^{* 1}$ A. R. Rabiee,† A. Gunn, ${ }^{*}$ and J. K. House* \\ *Livestock Veterinary Teaching and Research Unit, Faculty of Veterinary Science, School of Life and Environmental Sciences, \\ The University of Sydney, Camden NSW 2570, Australia \\ †Cow Signals Australia, Horsley 2530, NSW, Australia
}

\begin{abstract}
Lameness is a significant welfare concern for dairy farmers and a major contributing economic loss to the dairy industry. Information is limited on environmental and managerial risk factors associated with lameness in Australian dairy herds. The objective of this study was to explore and quantify the environmental and management risk factors associated with lameness in pasturebased dairy herds. A cross-sectional study was conducted in 63 pasture-based dairy herds between 2011 and 2014, where all lactating cows were locomotion scored (scale 1-4) during a single visit. Environmental and management variables, such as length of main track and animal handling practices, were recorded during the visit. The prevalence of lameness was measured for each farm and associated risk factors were analyzed using a Generalized Linear Model, where farm was the unit of analysis. Estimated average prevalence of lameness was $18.9 \%$ (range 5 to $44.5 \%$ ). The prevalence of lameness was associated with the amount of rainfall during the $30 \mathrm{~d}$ before the farm assessment, smoothness of concrete surface and available space per cow in the holding yard, and length of feed-pad available per cow. Inappropriate handling of cows on the track (e.g., causing sideways pushing among cows) was also a contributing risk factor to high prevalence of lameness in these dairy herds. The findings of this study suggest that by managing several environmental and farming practices, producers can reduce the prevalence of lameness, leading to improved productivity of their herds.
\end{abstract} Key words: lameness, risk factor, pasture, Australia

\section{INTRODUCTION}

Lameness along with mastitis and reproductive failure are recognized as the 3 costliest diseases in dairy herds. The costs incurred due to lameness are derived

Received March 7, 2016.

Accepted May 29, 2016.

${ }^{1}$ Corresponding author: shahab.ranjbar@sydney.edu.au from reduced milk production, compromised reproductive performance (Lucey et al., 1986; Barkema et al., 1994; Sprecher et al., 1997), culling (Collick et al., 1989), mortality (McConnel et al., 2008), and treatment. Lameness is also recognized as a significant animal welfare issue causing pain and compromising the ability of cows to express normal behavior (Webster, 1986; FAWC, 1997).

The etiology of lameness is multifactorial, and the risk factors associated with lameness may include cow, environmental, management, and nutrition factors. Cow risk factors include parity, breed, age, stage of lactation, body depth, udder depth, and rear leg side view (Wells et al., 1993a; Boelling and Pollott, 1998; Boettcher et al., 1998). Environmental and management risk factors include concrete surfaces (Bazeley and Pinsent, 1984; Somers et al., 2003), season (Wells et al., 1993b), frequency of hoof trimming (Espejo and Endres, 2007), maintenance of cow tracks, and inappropriate animal handling (Chesterton et al., 1989). Dietary risk factors that have been suggested to be associated with lameness and laminitis include clinical and subclinical ruminal acidosis and high protein/low fiber lush rye grass pastures (Vermunt and Greenough, 1994).

The majority of lameness studies reported in the literature originate from intensive housed dairy systems in North America and Europe. There are limited studies evaluating farm-level risk factors for lameness in pasture-based dairy herds. The objective of this study was to investigate the environmental and management risk factors associated with lameness at the herd level using a cross-sectional study of dairy herds in the state of New South Wales (NSW) in Australia. Our aim is to use the findings of this study and other available information to develop a herd lameness assessment package for pasture-based dairy herds and to translate the findings of this study into a tool that can be used by herd advisers and farm managers to identify the major risk factors to enable them to prioritize lameness management interventions. 


\section{MATERIALS AND METHODS}

\section{Farm Criteria and Visits}

A cross-sectional study ( $\mathrm{n}=63$ farms) was carried out to explore and quantify the association among environmental, farm-level management practices and prevalence of lameness in pasture-based dairy herds. Sixty-three pasture-based dairy herds milking 90 cows or more were identified across 4 dairy regions on the eastern coast of NSW and enrolled in the study to investigate the prevalence of lameness and associated risk factors. Study farms included both seasonal and nonseasonal calving herds, several farms used feed-pads, and none had facilities for housing cows. This study was approved by the Human Ethics Committee of the University of Sydney. Each herd was visited once, and the assessments were undertaken between June 2011 and June 2014. The same observer performed the locomotion scoring and collected environmental and farm practice variables during the visit.

\section{Environment Assessment}

Herd assessments and data collection were conducted using a data collection package developed by the study investigators. The package included a (1) herd data sheet, (2) investigator data sheet, and (3) locomotion scoring sheet.

Herd Data Sheet. Herd demographic data collected included the date of visit, farm address, predominant breed of cows, average daily milk production per cow, calving pattern, and feeding system.

Investigator Data Sheet. The investigator data sheet was used to record environmental and management data pertaining to the holding yard, track design, animal handling along the tracks and during milking, footbaths, and feed-pad.

Track Design and Herding Along Tracks. The main track was defined as the track identified by the farmer being used most frequently by cows during the year. The length of the main track was measured using a measuring wheel with an accuracy of $\pm 0.10 \mathrm{~m}$. The gradient of the main track was measured every $50 \mathrm{~m}$ using a 1-m level and a ruler. At these points, the width and slope of the main track were also measured. Overall steepness of the farm was also assessed along with other features such as water drainage and existence and efficiency of a dirt track-concrete barrier at the junction of main track and milking cow holding yard. The farm staff and cow interactions were also recorded, when cows were brought up to the milking parlor and during milking, particularly if cows were pushed or drifted toward the dairy and the behavior of cows during walking (e.g., high head carriage, excessive pushing, or reversing).

Foot Bath. Presence and the type of footbath were recorded along with the dimensions to calculate the volume of solution in the bath.

Feed-Pad. In those herds that used a feed-pad to feed a partial mixed ration before or after grazing, the length of feed-pad was measured to determine the available space per cow $(\mathrm{m} / \mathrm{cow})$. None of the feedpads had dividers or separators (such as vertical bars or headlocks) between the cows.

Holding Yard and Milking. A diagram of the holding yard was drawn and the total area was calculated. Once the gates to the holding yard were closed behind the last cows, the number of cows in the yard was calculated by subtracting the number of cows being milked and the number of cows that had already exited the dairy from the total number of cows in the milking herd. Space per cow was calculated according to yard area divided by number of cows in the yard. Holding yard gradient was measured at 4 points to calculate the mean gradient of the yard (points were at entrance to the yard, entrance to the parlor and the other 2 were between the 2 former points). The width of entrance from the track on to the holding yard was measured to calculate entrance width per 100 cows (i.e., 4-m entrance in a dairy milking 400 cows provides 1 -m entrance width per 100 cows). Holding yard surface was assessed and scored according to the method used by Faull et al. (1996), and the presence of concrete grooves was also noted.

The following parameters were recorded, when cows were brought up to the holding yard during afternoon milking time: (1) number of cows in the yard when the gates were shut, (2) number of cows holding their heads up (sign of limited space) in the holding yard when gates were shut, (3) duration of use of backing gate every time it was moved, (4) procedures that were used by farm personnel to push or move cows into the milking parlor, and (5) the total number of sharp turns that cows had to make when entering and exiting the milking parlor.

Locomotion Scoring. All lactating dairy cows were locomotion scored when cows exited the milking parlor. Due to the rate of cows exiting the milking parlor during locomotion scoring, the locomotion scores were recorded as a tally rather than on individual cows. The locomotion scoring system that was used in this study was a modified locomotion scoring system that has been developed by Nordlund et al. (2004). These modifications facilitated scoring of multiple cows at the same time when cows exited the dairy parlor, and we were able to score cows that seemed to have multilimb lameness (i.e., thin soles on both hind limbs). 
Table 1. Locomotion scoring system used to identify cows with lameness including classification of lameness ${ }^{1}$

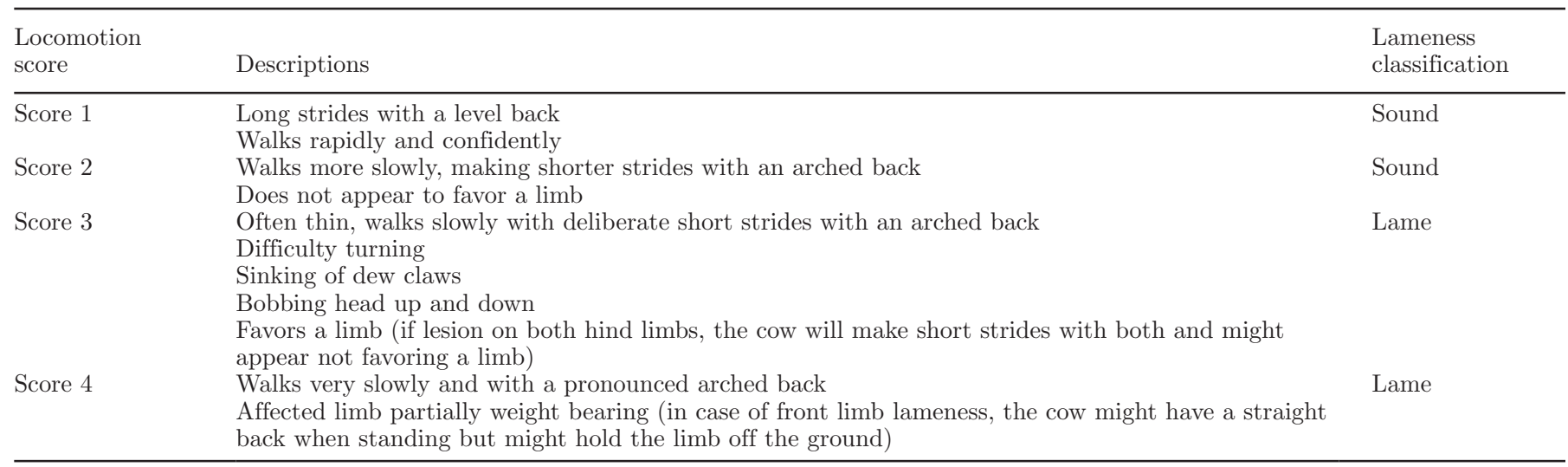

${ }^{1}$ Considerations taken into account while scoring are shown in parentheses.

These cows tend to have an arched back and take much shorter strides with both hind limbs but not favor a limb in particular. These cows were considered score 3 or 4 depending on the severity of lameness. In this system cows were scored on the scale of 1 to 4 , where 1 was considered as sound (healthy) and 4 was considered as severely lame (Table 1 ). Cows with scores 1 and 2 were pooled and were considered sound, and cows with scores 3 and 4 were also pooled and considered clinically lame for statistical analysis.

Rainfall. Daily rainfall data were downloaded from the Australian Bureau of Meteorology for each farm utilizing the closest weather station. The average daily rainfall for the 30-d period before farm assessment was chosen to measure the influence of rainfall on the risk of lameness. This period was selected to be consistent with previous studies conducted in the United Kingdom that concluded rainfall influences the risk of lameness (Eddy and Scott, 1980; Williams et al., 1986).

\section{Statistical Analysis}

The prevalence of lameness at the herd level was estimated using the number of cows with a locomotion score equal to or greater than 3 as the numerator and the total number of cows that were locomotion scored as the denominator. The statistical analysis was conducted using Stata software program (Stata/SE, v13, StataCorp LP, College Station, TX). To determine the statistical significance of a selection of potential risk factors for lameness, and assess the clinical significance of each factor, a generalized linear model was used. The magnitude of effect of potential risk factors (environmental and farm practices) were estimated using a generalized linear model, where the link function was logit, which will allow logistic regression for grouped binomial data. The family (binomial and herd size) was a binomial distribution and the number of cows within herds; this means that total number of cows in the herds $(\mathrm{N})$ was the variable containing the binomial denominator, allowing the number of cows scored in trial to vary across herds (www.stata.com/manuals13/ rglm.pdf).

To quantify the herd level risk factors influencing the prevalence of lameness, we specified a binary response variable $Y_{i}=1$ if the $i$ th cow was identified as lame and zero otherwise. In the first instance, a fixed-effects logistic regression model was used where the herd-level prevalence of lameness was parameterized as a function of $m$ herd-level explanatory variables. Given $p_{i}=\mathrm{P}\left(Y_{i}\right.$ $=1)$ and assuming that the $Y_{i}$ are mutually independent, this fixed-effects logistic regression model takes the form

$$
\log \left\{\frac{p_{i}}{1-p_{i}}\right\}=\alpha+\beta_{m} x_{m i}+\varepsilon_{i}
$$

where $\beta_{m}$ is the coefficient at the herd level, $x_{m i}$ is the explanatory variable at the herd level, and $\varepsilon_{i}$ is the residual. Univariable analyses were first performed to assess the association between the outcome variable and each of the putative risk factors. Predictors with a univariable association of $P \leq 0.20$ were submitted to a multivariable model. Predictor variables were removed from the final model if $P>0.05$ through manual backward elimination. This approach was used to select variables that best explained the probability of lameness at the herd level. If the removal of a variable changed the parameter estimate of any of the remaining predictors by $>30 \%$ on the logit scale, the eliminated variable was retained as a confounder regardless of its $P$-value (Dohoo et al., 2009). Parameter estimates are presented as odds ratios (OR) and 95\% CI. Region (a categorical variable comprised of 4 levels) was forced 
into the model because it was considered a priori to be a confounder (Perez-Cabal and Alenda, 2014). We were unable to investigate the interactions among some of the variables because of an imbalanced number of observations within each subgroup leading to inadequate statistical power. The results of the final multivariable model are reported in terms of estimated odds ratios and $95 \%$ CI for each explanatory variable.

\section{RESULTS AND DISCUSSION}

\section{Descriptive Analysis}

A total of 63 pasture-based dairy herds with or without feed-pad were visited over a 3-yr period (20112014) and 18,960 cows were locomotion scored. Visits were conducted across all seasons on the selected farms along the eastern coast of NSW $(920 \mathrm{~km})$ in 4 different dairy regions. Herd and farm variables and their categories considered in the univariate and multivariate analysis are presented in Table 2. A descriptive analysis of putative risk factors is provided in Table 3. The average herd size (milking cows) was 300 and ranged from 90 to 1,025. Farmer estimated average daily walking distance in these herds was $2.6 \mathrm{~km}(0.8-5.5 \mathrm{~km})$. Estimated prevalence of cows with lameness was $18.9 \%$ (range 5-44.5\%). In 58 dairy herds (92\%), cows with score 2 were the largest group of cows. Prevalence (\%) of locomotion scores is shown in Figure 1.

To our knowledge, no other studies have reported the prevalence of lameness in Australian dairy herds. The mean prevalence of lameness observed in this study (18.9\%) was higher than reported by Fabian et al. (2014) of $8.3 \%(1.2-36 \%)$ for grazing herds in New Zealand. The prevalence of lameness in the current study was similar to or lower than that reported from other countries where cattle are housed. A study by Cook (2003) in Wisconsin on freestall and tie-stall dairies showed that the prevalence of lameness was seasonal and varied from 21.1 to $23.9 \%$. A similar prevalence of lameness was reported in Canada by Solano et al. (2016) who performed a study on 141 freestall dairies in 3 provinces finding the average prevalence of lameness ranged between 19.6 to $24.2 \%$. The prevalence of lameness in European herds appears more variable. Clarkson et al. (1996) reported a lameness prevalence of $20.6 \%$ in Wales, with a range of 2 to $53.9 \%$ illustrating significant variation between farms. A United Kingdom study found that the prevalence of lameness in zero-grazing herds (39\%) was higher than confinement herds that allowed cows to graze during warmer months (15\%; Haskell et al., 2006). The high prevalence of lameness reported by Haskell et al. (2006) on UK freestall farms is consistent with a study by Barker et al. (2010) who found that the prevalence of lameness was $36.8 \%$ among 205 freestall dairies in England and Wales.

\section{Univariable and Multivariable Analysis}

Our primary focus in this study was to investigate herd-level risk factors that have been anecdotally suggested to contribute to the prevalence of lameness in confinement or pasture-based dairy production systems. These included farming practice, animal handling (human-cow interactions), and several nutritional components. The results of univariable analysis are presented in Appendix Table A1.

Potential limitations of the study relating to study design include the use of a single locomotion assessment and a single assessor. Performing a single locomotion score provided a snapshot in time rather than a measure of lameness prevalence over time. Short-term changes such as rainfall may cause changes in the prevalence of lameness. The logistics of repeated locomotion scoring was beyond the scope of this study. Utilizing a single assessor across farms provided for consistency of farm risk assessments and locomotion scoring. Conversely, as measurement of risk factors was not independent of locomotion scoring, it presents a potential opportunity for bias.

Limitations related to findings in the study included difficulties with meaningful assessment of tracks and inadequate sample size to evaluate some factors. Studies conducted in New Zealand identified track maintenance as one of the most important risk factors for lameness (Chesterton et al., 1989). Crowning of dairy tracks is recommended to provide water drainage from the surface of tracks to the adjacent paddocks. In this study dairy track assessment was attempted. However, intrafarm intra-track variability in crowning slope made it difficult to provide a meaningful measurement of this variable, hence it was not investigated in our study. The contribution of presence or absence of footbath to the risk of lameness was not fully investigated because only 3 farms had a footbath and only 2 were using the footbath on a regular basis. Similarly, only 18 farms (out of 63 farms) used feed-pads to feed partial mixed ration before or after grazing. Therefore, we were unable to investigate the association between the presence or absence of feed-pads and prevalence of lameness in the multivariable model.

\section{Herding Along the Tracks}

In our study the behavior of cows was observed as they were brought up to the dairy parlor for milking. Elevated head carriage and cow-to-cow pushing reflect- 
ing excessive pushing by the staff or dogs was recorded. The odds of lameness in those herds, where appropriate animal handling was practiced, was far less (OR: 0.56; 95\% CI: $0.43,0.71 ; P<0.001$, Table 4) than those with rough cattle handling practices. These findings are consistent with the results of case-control studies on 62 New Zealand pasture-based dairy farms, where track maintenance and animal handling were found to be the main risk factors for the prevalence of lameness
(Chesterton et al., 1989). Chesterton (2015) reports that cows predominantly avoid sideways pushing; however, dominant cows tend to push between other cows when they are mishandled. It has been proposed that inappropriate animal handling practices with constant pushing of cows can lead to increased congestion of the cows at the back of the herd which results in cows holding their heads up leading to poor foot placement. It has been shown in New Zealand dairy herds that ap-

Table 2. Categories of risk factors considered for inclusion in univariable and multivariable statistical analysis

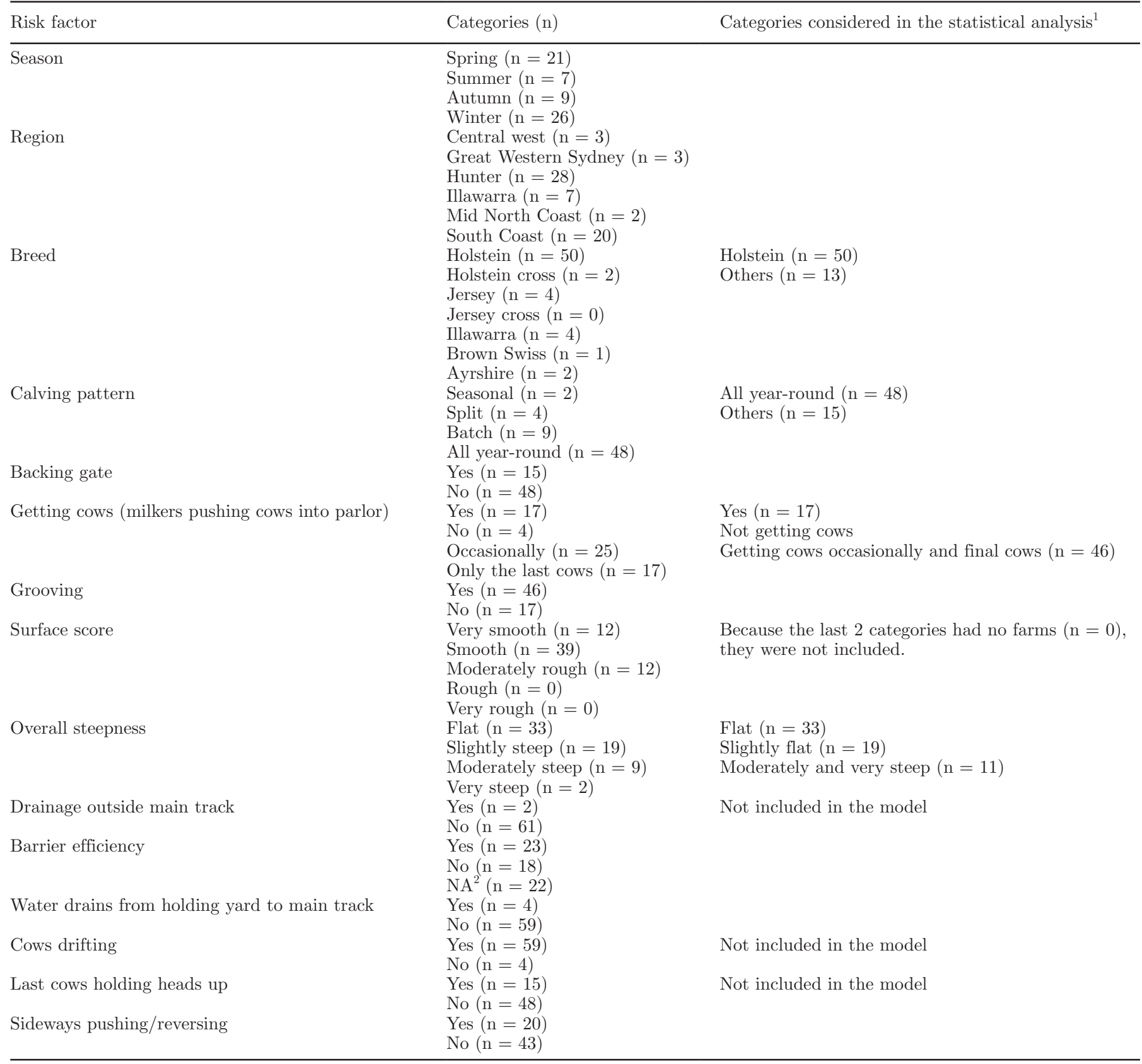

${ }^{1}$ Due to imbalanced numbers of cows in different categories, these variables were recategorized or excluded from the analysis.

${ }^{2} \mathrm{NA}=$ not applicable. 
Table 3. Descriptive statistics of continuous variables considered as potential risk factors for lameness in pasture-based dairy herds

\begin{tabular}{lc}
\hline Risk factor & N average (range) \\
\hline Walking distance $(\mathrm{n}=62 ; \mathrm{km} / \mathrm{d})$ & $2.64(0.8-5.5)$ \\
Average milk yield $(\mathrm{n}=63 ; \mathrm{L} / \mathrm{d})$ & $23.70(12-43)$ \\
Average peak of milk yield $(\mathrm{n}=62 ; \mathrm{L} / \mathrm{d})$ & $34.20(16-70)$ \\
Average rainfall in last $30 \mathrm{~d}(\mathrm{n}=63 ; \mathrm{mm})$ & $2.23(0-11.2)$ \\
Yard gradient $(\mathrm{n}=58 ; \%)$ & $3.85(1.8-9.6)$ \\
Main track length $(\mathrm{n}=62 ; \mathrm{m})$ & $460.11(128.00-1,017.10)$ \\
Main track width $(\mathrm{n}=62 ; \mathrm{m})$ & $9.89(3.60-20.00)$ \\
Main track gradient $(\mathrm{n}=62 ; \%)$ & $3.23(0-12.5)$ \\
Number of cows per meter width of the main track $(\mathrm{n}=62 ;$ no. $)$ & $35.40(6.75-108.28)$ \\
Feed-pad length available per cow $(\mathrm{n}=18 ; \mathrm{m})$ & $0.59(0.17-1.00)$ \\
Holding yard space available per cow $\left(\mathrm{n}=62 ; \mathrm{m}^{2}\right)$ & $1.67(0.78-3.49)$ \\
Cows holding heads up before milking $(\mathrm{n}=63 ; \%)$ & $0.10(0.0-1.00)$ \\
Entrance gate width $(\mathrm{n}=62 ; \mathrm{m})$ & $6.14(2.4-15)$ \\
Entrance gate width available for every 100 cows $(\mathrm{n}=62 ; \mathrm{m})$ & $2.41(0.77-5.83)$ \\
Number of cows per unit of milking $(\mathrm{n}=63 ;$ no. $)$ & $11.4(4.2-23.2)$ \\
Amount of grain fed $(\mathrm{n}=61 ; \mathrm{kg} / \mathrm{d})$ & $6.36(3-14)$ \\
\hline
\end{tabular}

propriate handling of cattle on tracks and allowing them to drift toward the milking parlor at their own pace can reduce the prevalence of lameness (Sauter-Louis et al., 2004). These recommendations have been incorporated into farming guidelines on stress-free movement and handling of cows (Chesterton, 2015). The results of the current study support these recommendations. Rough handling of lactating cows has also been reported by Amstutz (1985) as a major recurrent management issue in dairy herds.

\section{Milking and Holding Yard}

Potential risk factors considered for lameness attributable to conditions in the milking yard, included cow behavior (as an indicator of poor handling), space per cow in the holding yard and the surface score of the concrete (smoothness and grooving). Every square meter increase in the available space per cow in the hold-

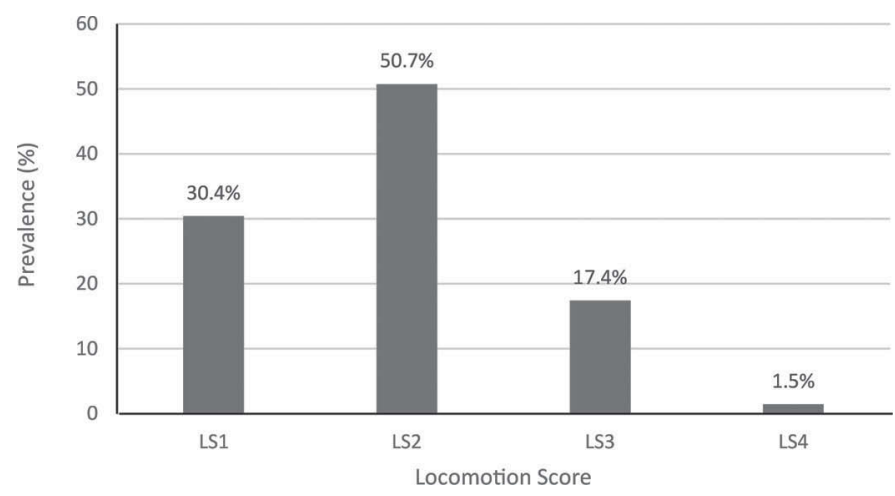

Figure 1. The prevalence (\%) of locomotion scores (LS) across all study farms on a scale of 1 to 4 , where 1 was considered as sound (healthy) and 4 was considered as severely lame. ing yard reduced the odds of lameness by $33 \%$ (OR: $0.67 ; 95 \%$ CI: $0.56,0.81 ; P<0.001$, Table 4$)$. This is particularly important as dominant cows tend to walk and be positioned in their desired milking order by pushing among the less dominant cows (Sauter-Louis et al., 2004). Having more space for less dominant cows reduces the frequency of contacts and provides room to avoid dominant cows pushing through to their desired milking order. Our observations in dairy herds with low prevalence of lameness support these assertions. In these herds, cows in the holding yards could move back freely in the presence of dominant cows at the entrance of the milking parlor. These findings have practical application in dairy herds and demonstrate that the design of milking yards could be a limiting factor for steady flow of cows without pushing or increased competition. This indicates that improving the milking yard and increasing available space per cows can be beneficial and will potentially reduce the prevalence of lameness in dairy herds. Nevertheless, these findings are not in agreement with the findings of Chesterton et al. (1989), where the prevalence of lameness was higher in herds with greater available space per cow (1.27 vs. $1.08 \mathrm{~m}^{2}$ space per cow). He speculated that the reason for higher prevalence of lameness in farms with more space per cow could be due to more movement and increased probability of foot injuries. However, Chesterton also found that the risk of lameness was associated with backing gate use, suggesting that yard area may not have reflected available or "effective" space over the course of milking in some herds (Chesterton et al., 1989).

We found that the odds of lameness was lower (OR: $0.56 ; 95 \%$ CI: $0.43,0.75, P<0.001$, Table 4 ) in dairy herds where the cows did not hold their heads up in the milking yard before milking compared with those 
herds in which cows held their heads up before milking (when the holding yard gates were shut). This could be due to ample space per cow in the milking yard. Higher prevalence of lameness in herds where a proportion of cows were holding their heads up were predominantly observed in those herds with obstacles in the milking yard. These obstacles included gates in the middle of milking yard that can disrupt cow movement, herds with extra gates or rails in the holding yard, and herds with a circular holding yard where the entrance was in the middle of the milking yard.

The estimated odds of lameness in herds on both smooth (score $=2$; OR: $1.42 ; 95 \%$ CI: $1.08,1.89 ; P=$ 0.12 , Table 4$)$ and rough ( CI: $1.31,1.97 ; P<0.001$, Table 4) concrete surfaces were greater than those on very smooth concrete surface ( score $=1$ ) in the milking yard. These findings contradict the common assumptions that the level of smoothness of holding yard is associated with the prevalence of lameness. It appears that the interaction between grooved surface and smoothness of surface may have partially contributed to different outcomes in our study. However, due to the imbalanced structure of data on milking yard smoothness scores and grooves, it was not appropriate to statistically assess the significance of grooving or the interaction between the presence or absence of grooving and the surface scores of milking yards. The pattern of grooving and properties of the grooves were not assessed in this study, because there were marked differences within and between herds (e.g., some farms had up to 5 different types of grooving patterns in their milking yard). Another factor that may have contributed to a lower prevalence of lameness in very smooth milking yards is farm management, as farm personnel may tend to implement more appropriate cow handling practices in these milking yards compared with those with a rougher surface. It has also been reported that cows walking on

Table 4. Multivariable logistic regression (as part of generalized linear model) of risk factors associated with the prevalence of lameness in lactating dairy herds in the state of New South Wales in Australia

\begin{tabular}{|c|c|c|}
\hline Risk factors & $\begin{array}{l}\text { Odds ratio } \\
(95 \% \text { CI })\end{array}$ & $P$-value \\
\hline \multicolumn{3}{|l|}{ Sideway pushing among cows when herding } \\
\hline Space per cow in holding yard $\left(\mathrm{m}^{2}\right)$ & 0.67 & $<0.001$ \\
\hline & $(0.56,0.81)$ & \\
\hline \multicolumn{3}{|c|}{ Cows in holding yard holding head up just before milking started/when gate to holding yard was closed } \\
\hline Yes & 1 & - \\
\hline No & $\begin{array}{l}0.57 \\
(0.43,0.75)\end{array}$ & $<0.001$ \\
\hline \multicolumn{3}{|l|}{ Surface score } \\
\hline 1 (very smooth) & 1 & - \\
\hline 2 (smooth) & $\begin{array}{l}1.43 \\
(1.08,1.89)\end{array}$ & 0.12 \\
\hline Average daily milk (L) & $\begin{array}{l}1.04 \\
(1.02,1.05)\end{array}$ & $<0.001$ \\
\hline \multicolumn{3}{|l|}{ Main breed } \\
\hline Holstein & 1 & - \\
\hline Other breeds & $\begin{array}{l}0.77 \\
(0.58,1.03)\end{array}$ & 0.074 \\
\hline \multicolumn{3}{|l|}{ Calving system } \\
\hline Year-round & 1 & - \\
\hline Other & $\begin{array}{l}1.17 \\
(0.97,1.41)\end{array}$ & 0.099 \\
\hline \multicolumn{3}{|l|}{ Region $^{1}$} \\
\hline (Reference) Region 1 & 1.0 & - \\
\hline Region 2 & $\begin{array}{l}0.68 \\
(0.34,1.37)\end{array}$ & 0.281 \\
\hline
\end{tabular}

${ }^{1}$ Central West and Great Western Sydney (Region 1), Hunter and Mid North Coast (Region 2), Illawarra and South Coast (Region 3). 
very smooth surfaces are generally more cautious and walk with a stiff gait which may lead to less slipping, cow-to-cow contact, and lameness (Phillips and Morris, 2001). It has been suggested that rough uneven surfaces may transfer weight bearing to point pressure areas on the sole rather than the wall, which is the strongest part of the claw capsule, increasing the frequency of abrasions and sole bruising (Phillips and Morris, 2001; Telezhenko et al., 2008). It is anticipated that cows are more cautious and less vigorous when walking on very smooth surface in the holding yard; however, the converse is also possible because stockman may push cows harder on rough surface due to lower probability of cows slipping and falling on rough surfaces.

The odds of lameness in herds with predominantly Holstein-Friesians ( $\mathbf{H F}$ ) cows tended to be greater than the other breeds combined (OR: $0.77 ; 95 \%$ CI: 0.58 , 1.03, $P=0.074$, Table 4 , HF cows were the reference group). The breed of cattle has previously been reported as a risk factor for lameness in other studies. The Jersey cows (Alban, 1995; Baranski et al., 2008) and crossbred cattle had a lower risk of lameness compared with HF cows (Barker et al., 2010). In our study, due to the small number of herds with other breeds $(\mathrm{n}=$ 13) than HF, we were unable to demonstrate if breed can be considered as a potential risk factor at the $\alpha=$ 0.05 level.

The odds of lameness in herds with feed-pads appear to be associated with the length of feed-pad available per cow $(\mathrm{m} /$ head; OR $=0.68$; CI 95\%: 0.55, 0.84; $P<$ 0.001 , Table 4), indicating the prevalence of lameness is lower in those herds where more feeding space is available per cow. The majority of herds with feed-pads $(\mathrm{n}=18)$ in this study were established on a concrete surface, and the rough concrete surface can contribute to trauma and claw horn lesions (Cook et al., 2004). Competition between cows during the feeding period at a feed-pad with inadequate space per cow can be associated with more pushing and twisting on their feet, which can cause abrasion and injuries to the claws and consequently lameness. In the current study, the estimated average feeding space per cow at the feed-pad was $0.59 \mathrm{~m}$ (range $0.17-1.0 \mathrm{~m}$ ). It has been demonstrated that feed-pads with more feeding space per cow (0.75 and $1 \mathrm{~m}$ per cow) reduces the competition and aggressiveness between cows, which in turn improves their feeding behavior (Hetti Arachchige et al., 2014).

\section{Environment and Cow Factors}

We explored the effect of both the amount of rainfall and season on the prevalence of lameness. In contrast to lameness studies in other countries, season was not a significant risk factor for lameness in NSW pasturebased dairy herds. The winter season in North America and Europe is predominantly associated with higher rainfall, lower temperature, and an increased risk of lameness (Cook, 2003). The seasonal rainfall data obtained from the Australian Bureau of Meteorology during the period of this study (3 yr) showed that there were significant variations in annual rainfall among the regions in different years and seasons, and inconsistent relationship among temperature, rainfall, and season. The odds of lameness increased with increasing average daily rainfall during the $30 \mathrm{~d}$ before the farm assessment $(\mathrm{OR}=1.06,95 \% \mathrm{CI}: 1.02,1.09 ; P=0.001$, Table 4). These findings are consistent with the study of Williams et al. (1986) in the United Kingdom, who showed that wet weather was a significant risk factor for lameness in pasture-based dairy herds. Clarkson et al. (1996) found that in Wales and western England the prevalence of lameness $(25 \%)$ during the winter time was greater than the summer time (18.6\%). Several studies have investigated the effect of moisture on the hardness of claw horn (Vermunt and Greenough, 1995). Prolonged exposure to water makes the claws softer and more prone to injuries. Cows with softer claws tend to have more severe claw lesions than cows with harder claws (Borderas et al., 2004). It has been suggested to keep cows in conditions that allow for dry hooves as much as possible (Borderas et al., 2004); however, claws of cows in pasture-based dairy herds are constantly exposed to moisture during the wet months. We speculate that this constant exposure has contributed to the higher locomotion scores found in our study.

For every 1-L increase in average daily milk production, the odds of lameness increased by $4 \%(\mathrm{OR}=1.04$, 95\% CI: 1.02, 1.05; Table 4). These findings are supported by other studies (Deluyker et al., 1991; Green et al., 2002; Bicalho et al., 2008) that investigated the association between the level of milk production and prevalence of lameness in confined herds. Hansen et al. (1979) found that in herds with high genetic merit, high milk yield was positively associated with the incidence of lameness. In the current study, herd was the unit of analysis and we did not have access to production data for individual cows and were unable to include cow risk factors such as parity, productivity, and health status of cows in the analysis. Therefore, it is important to consider the ecological fallacy that these findings may not accurately represent the relationship between milk yield and prevalence of lameness in lactating dairy herds at the cow level and should be interpreted with caution.

Nutrition is reported to be an important risk factor for lameness (Manson and Leaver, 1988; Livesey 
et al., 1998). Various lesions resulting in lameness are proposed to be due to laminitis (Greenough, 1990). Despite extensive research on laminitis, its etiology is still unclear (Danscher et al., 2009). One of the proposed risk factors for laminitis is dairy rations high in readily fermentable carbohydrate. Christmann et al. (2002) demonstrated this by inducing laminitis through feeding excessive amounts of grain to steers. Coombe et al. (2013) compared claw health of cows offered pasture silage in the paddock and also fed grain-based partial mixed ration at the feed-pad and grain in morning and afternoon milking times during early, mid, and late lactation. They found that different feeding systems or amount of supplements did not significantly influence the prevalence of the common lesions such as white line disease, paint brush hemorrhaging, and bruising. In the current study, the amount of grain or pellets fed per head per day on each dairy was recorded to be an average of $6.36 \mathrm{~kg}$ (ranged from 3 to $14 \mathrm{~kg}$ per cow per day, Table 2); however, the amount fed was not found to be significantly associated with the risk of lameness.

The association between milk composition (fat and protein percentage) that was obtained from monthly herd recording of selected farms was initially explored in a univariable analysis. The univariable analysis showed that the prevalence of lameness was higher $(P=0.002$, Appendix Table A1) in herds with lower monthly average milk protein. We cautiously examined this association; however, due to the lag time between the day of the visit and monthly herd recording in most participating herds, this variable was not considered in the multivariable model and deserves further investigation.

\section{CONCLUSIONS}

The results of this cross-sectional study provided an insight on potential environmental, managerial, and production risk factors associated with lameness in pasture-based dairy herds in NSW, Australia. Identifying and quantifying the relative contribution of risk factors for lameness helps dairy farmers, cattle veterinarians, and farm consultants to prioritize resources for cost-effective lameness prevention. Management, facility, environmental, and cow factors were observed to contribute to the risk of lameness. Notably the risk of lameness is largely influenced by cow handling as cows are brought up to the dairy and by the degree of crowding within the holding yard before milking. Scenarios associated with cows lifting their heads and pushing sideways increases the risk of lameness. The result of the study indicates a significant minimal cost opportunity to reduce lameness through good stock handling.

\section{REFERENCES}

Alban, L. 1995. Lameness in Danish dairy cows: Frequency and possible risk factors. Prev. Vet. Med. 22:213-225.

Amstutz, H. E. 1985. Prevention and control of lameness in dairy cattle. Vet. Clin. North Am. Food Anim. Pract. 1:25-37.

Baranski, W., T. Janowski, and S. Zdunczyk. 2008. Incidence of reproduction disorders, clinical mastitis and lameness in cross-breed HF $\mathrm{x}$ BW cows and Jersey cows maintained in the same conditions. Med. Weter. 64:1201-1204.

Barkema, H. W., J. D. Westrik, K. A. S. V. Keulen, Y. H. Schukken, and A. Brand. 1994. The effects of lameness on reproductive performance, milk production and culling in Dutch dairy farms. Prev. Vet. Med. 20:249-259.

Barker, Z. E., K. A. Leach, H. R. Whay, N. J. Bell, and D. C. Main. 2010. Assessment of lameness prevalence and associated risk factors in dairy herds in England and Wales. J. Dairy Sci. 93:932-941.

Bazeley, K., and P. Pinsent. 1984. Preliminary observations on a series of outbreaks of acute laminitis in dairy cattle. Vet. Rec. 115:619 622 .

Bicalho, R. C., L. D. Warnick, and C. L. Guard. 2008. Strategies to analyze milk losses caused by diseases with potential incidence throughout the lactation: A lameness example. J. Dairy Sci. 91:2653-2661.

Boelling, D., and G. E. Pollott. 1998. Locomotion, lameness, hoof and leg traits in cattle I. Phenotypic influences and relationships. Livest. Prod. Sci. 54:193-203.

Boettcher, P. J., J. C. M. Dekkers, L. D. Warnick, and S. J. Wells. 1998. Genetic analysis of clinical lameness in dairy cattle. J. Dairy Sci. 81:1148-1156.

Borderas, T. F., B. Pawluczuk, M. de Passillé, and J. Rushen. 2004. Claw hardness of dairy cows: Relationship to water content and claw lesions. J. Dairy Sci. 87:2085-2093.

Chesterton, N. 2015. Low stress dairy with Neil Chesterton. Accessed Sep. 20, 2015. http://www.lamecow.co.nz/lsarticles.shtml.

Chesterton, R. N., D. U. Pfeiffer, R. S. Morris, and C. M. Tanner. 1989. Environmental and behavioural factors affecting the prevalence of foot lameness in New Zealand dairy herds - A case-control study. N. Z. Vet. J. 37:135-142.

Christmann, U., E. B. Belknap, H. C. Lin, and J. K. Belknap. 2002. Evaluation of hemodynamics in the normal and laminitic bovine digit. Pages 165-166 in Proc. 12th Int. Symp. on Lameness in Ruminants, Orlando, Florida.

Clarkson, M. J., D. Y. Downham, W. B. Faull, J. W. Hughes, F. J. Manson, J. B. Merritt, R. D. Murray, W. B. Russell, J. E. Sutherst, and W. R. Ward. 1996. Incidence and prevalence of lameness in dairy cattle. Vet. Rec. 138:563-567.

Collick, D. W., W. R. Ward, and H. Dobson. 1989. Associations between types of lameness and fertility. Vet. Rec. 125:103-106.

Cook, N. B. 2003. Prevalence of lameness among dairy cattle in Wisconsin as a function of housing type and stall surface. J. Am. Vet. Med. Assoc. 223:1324-1328.

Cook, N. B., K. V. Nordlund, and G. R. Oetzel. 2004. Environmental influences on claw horn lesions associated with laminitis and subacute ruminal acidosis in dairy cows. J. Dairy Sci. 87(Suppl.):E36E46.

Coombe, J. E., M. F. Pyman, P. D. Mansell, M. J. Auldist, G. A. Anderson, W. J. Wales, J. Malmo, M. J. Conley, and A. D. Fisher. 2013. The effects on claw health of supplement feeding grazing dairy cows on feed pads. Vet. J. 198:672-677.

Danscher, A. M., J. M. Enemark, E. Telezhenko, N. Capion, C. T. Ekstrom, and M. B. Thoefner. 2009. Oligofructose overload induces lameness in cattle. J. Dairy Sci. 92:607-616.

Deluyker, H. A., J. M. Gay, L. D. Weaver, and A. S. Azari. 1991. Change of milk yield with clinical diseases for a high producing dairy herd. J. Dairy Sci. 74:436-445.

Dohoo, I., W. Martin, and H. Stryhn. 2009. Model-Building Strategies. 2nd ed. Veterinary Epidemiologic Research. VER Inc., Charlottetown, PEI, Canada.

Eddy, R. G., and C. P. Scott. 1980. Some observations on the incidence of lameness in dairy cattle in Somerset. Vet. Rec. 106:140-144. 
Espejo, L. A., and M. I. Endres. 2007. Herd-level risk factors for lameness in high-producing Holstein cows housed in freestall barns. J. Dairy Sci. 90:306-314.

Fabian, J., R. A. Laven, and H. R. Whay. 2014. The prevalence of lameness on New Zealand dairy farms: A comparison of farmer estimate and locomotion scoring. Vet. J. 201:31-38.

Faull, W. B., R. D. Murray, W. B. Russell, J. E. Sutherst, and W. R Ward. 1996. Epidemiology of lameness in dairy cattle: The influence of cubicles and indoor and outdoor walking surfaces. Vet. Rec. 139:130-136.

FAWC. 1997. Report on the Welfare of Dairy Cattle. Farm Animal Welfare Council, London, UK.

Green, L. E., V. J. Hedges, Y. H. Schukken, R. W. Blowey, and A. J. Packington. 2002. The impact of clinical lameness on the milk yield of dairy cows. J. Dairy Sci. 85:2250-2256.

Greenough, P. R. 1990. Observations on bovine laminitis. In Pract. 12:169-173.

Hansen, L. B., C. W. Young, K. P. Miller, and R. W. Touchberry. 1979. Health care requirements of dairy cattle. I. Response to milk vield selection. J. Dairy Sci. 62:1922-1931.

Haskell, M. J., L. J. Rennie, V. A. Bowell, M. J. Bell, and A. B. Lawrence. 2006. Housing system, milk production, and zero-grazing effects on lameness and leg injury in dairy cows. J. Dairy Sci. 89:4259-4266

Hetti Arachchige, A. D., D. Fisher, W. J. Wales, M. J. Auldist, M. C. Hannah, and E. C. Jongman. 2014. Space allowance and barriers influence cow competition for mixed rations fed on a feed-pad between bouts of grazing. J. Dairy Sci. 97:3578-3588.

Livesey, C. T., T. Harrington, A. M. Johnston, S. A. May, and J. A Metcalf. 1998. The effect of diet and housing on the development of sole haemorrhages, white line haemorrhages and heel erosions in Holstein heifers. Anim. Sci. 67:9-16.

Lucey, S., G. J. Rowlands, and A. M. Russell. 1986. The association between lameness and fertility in dairy cows. Vet. Rec. 118:628631

Manson, F. J., and J. D. Leaver. 1988. The influence of concentrate amount on locomotion and clinical lameness in dairy cattle. Anim. Prod. 47:185-190.

McConnel, C. S., J. E. Lombard, B. a. Wagner, and F. B. Garry. 2008 Evaluation of factors associated with increased dairy cow mortality on United States dairy operations. J. Dairy Sci. 91:1423-1432.
Nordlund, K. V., N. B. Cook, and G. R. Oetzel. 2004. Investigation strategies for laminitis problem herds. J. Dairy Sci. 87:E27-E35.

Perez-Cabal, M. A., and R. Alenda. 2014. Clinical lameness and risk factors in a Spanish Holstein population. Livest. Sci. 164:168-174.

Phillips, C. J., and I. D. Morris. 2001. The locomotion of dairy cows on floor surfaces with different frictional properties. J. Dairy Sci. 84:623-628.

Sauter-Louis, C. M., R. Chesterton, and D. U. Pfeiffer. 2004. Behavioural characteristics of dairy cows with lameness in Taranaki, New Zealand. N. Z. Vet. J. 52:103-108.

Solano, L., H. W. Barkema, E. A. Pajor, S. Mason, S. J. LeBlanc, C. G. R. Nash, D. B. Haley, D. Pellerin, J. Rushen, A. M. de Passille, E. Vasseur, and K. Orsel. 2016. Associations between lying behavior and lameness in Canadian Holstein-Friesian cows housed in freestall barns. J. Dairy Sci. 99:2086-2101.

Somers, J. G. C. J., K. Frankena, E. N. Noordhuizen-Stassen, and J. H. M. Metz. 2003. Prevalence of claw disorders in Dutch dairy cows exposed to several floor systems. J. Dairy Sci. 86:2082-2093.

Sprecher, D. J. J., D. E. E. Hostetler, and J. B. B. Kaneene. 1997. A lameness scoring system that uses posture and gait to predict dairy cattle reproductive performance. Theriogenology 47:1179-1187.

Telezhenko, E., C. Bergsten, M. Magnusson, M. Ventorp, and C. Nilsson. 2008. Effect of different flooring systems on weight and pressure distribution on claws of dairy cows. J. Dairy Sci. 91:18741884

Vermunt, J. J., and P. R. Greenough. 1994. Predisposing factors of laminitis in cattle. Br. Vet. J. 150:151-164

Vermunt, J. J., and P. R. Greenough. 1995. Structural characteristics of the bovine claw: Horn growth and wear, horn hardness and claw conformation. Br. Vet. J. 151:157-180.

Webster, J. 1986. Health and welfare of animals in modern husbandry systems-dairy cattle. In Pract. 8:85-89.

Wells, S. J., A. M. Trent, W. E. Marsh, P. G. McGovern, and R. A. Robinson. 1993a. Individual cow risk factors for clinical lameness in lactating dairy cows. Prev. Vet. Med. 17:95-109.

Wells, S. J., A. M. Trent, W. E. Marsh, and R. A. Robinson. 1993b. Prevalence and severity of lameness in lactating dairy cows in a sample of Minnesota and Wisconsin herds. J. Am. Vet. Med. Assoc. 202:78-82.

Williams, L. A., G. J. Rowlands, and A. M. Russell. 1986. Effect of wet weather on lameness in dairy cattle. Vet. Rec. 118:259-261. 


\section{APPENDIX}

Table A1. Univariable analysis of environmental and managerial risk factors associated with the prevalence of lameness in lactating dairy herds

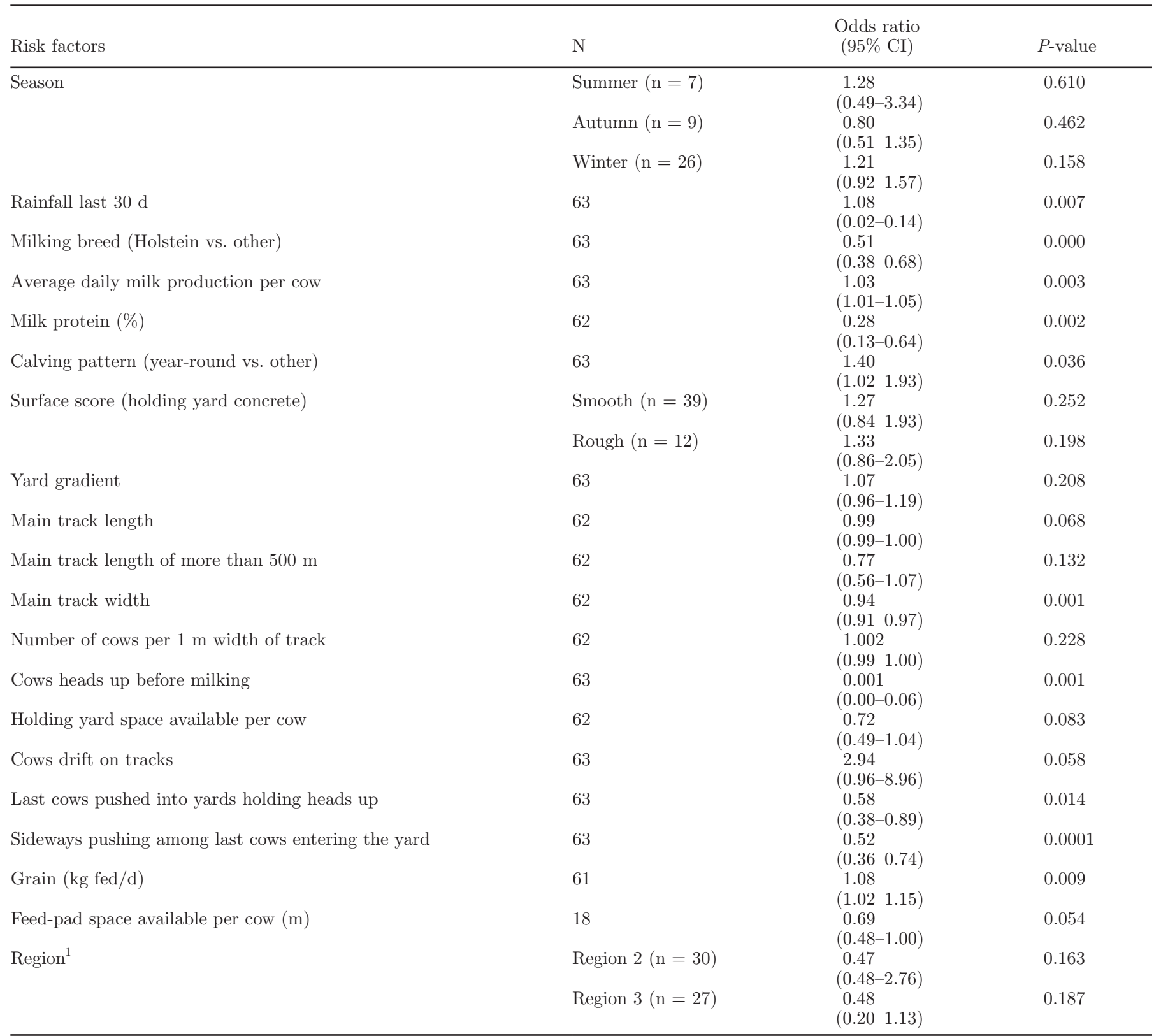

${ }^{1}$ Hunter and Mid North Coast (Region 2), Illawarra and South Coast (Region 3). 